\title{
Workforce Development, a Mechanism for Stimulating Economic Growth in Albania
}

\author{
Amalia Tola \\ Phd candidate, Agricultural University of Tirana, Faculty of Economy and Agribusiness \\ Email: amaliatola@hotmail.com
}

\author{
Doi:10.5901/mjss.2015.v6n4p403
}

\begin{abstract}
This article aims to explore the concept of workforce development as an effective approach that provides great impact to economic growth. Literature has proven that workforce development creates greater benefits for economic growth, especially at times of economic constraints. Although there have been more than 20 years since the collapse of the communist system, Albania is still facing times of difficult economic conditions. Recent reforms of the government for improving the quality of higher education and promoting vocational training would not provide any sustainable impact if there is no coordination between different stakeholders. Workforce development aims at creating such cooperation between stakeholders for a wide range of activities, policies and programs in order to sustain and retain a viable workforce that can support current and future industry requirements. Workforce development contributes to lifelong learning, development of proper skills and expertise which can be beneficial to the country economic development and social welfare, especially considering the globalization phenomenon and Albania's potential in the region.
\end{abstract}

Keywords: workforce, workforce development, human capital, lifelong learning, economic development.

\section{Introduction}

Human capital development is key to the economic success of a country as it contributes to the enhancement of the potential for growth and improved productivity, therefore human development strategies are placed more and more under focus with the growing globalization effect.

Workforce development can be strongly linked to lifelong learning philosophy. In a global economy the demands are shifting and many individuals need to reconsider their area of expertise, upgrade or learn new skills, therefore the workforce development approach comes closely at hand for greater impact.

Although the concept of workforce is not new, the concept of workforce development has been initially used in 1995 when Harrison, Weiss and Gant drew a distinction between 'employment training' which emphasizes the skills supply side and 'workforce development' which aims to explore the nature of employer demand. The concept of workforce development directs attention to the way in which companies collaborate with other organizations, particularly labor market intermediaries, and the ways in which they source, recruit and develop labor (Sutton, 2001). The aim of workforce development has to do with a wide range of activities, policies and programs in order to sustain and retain a viable workforce that can support current and future industry requirements. Workforce development approach contributes to the achievement of a skilled and productive workforce by reducing the gap between the skills demanded by employers and those supplied by the workforce.

\section{Research Objectives}

It has become increasingly clear that the well-being of nations, considered from both economic and social perspective, is dependent in a large measure on human resources (Ashton \& Green, 1999). The economic challenges that Albania is facing, especially related to employment, education and economic growth, raise the dilemma of how far the quality provided either by higher education and vocational education matches what the labor market demands in terms of knowledge, skills and capacities. International experience has shown that if the provision of skills is not appropriately linked with market needs, the impact on growth and development is not maximized. The workforce development approach has resulted in positive contribution to human capital development, especially at times of economic difficulties; therefore such approach can be beneficial for Albania considering the level of economic development and challenges for growth. 
This article aims to raise the awareness on workforce development, amongst academics and policy makers in Albania, by exploring the concept of workforce development and different models implemented in other countries. The article explores also the project 'Rritje Albania' which has placed a special focus on workforce development in four export oriented industries in the country. The approach used by this project is unique for Albania, considering the methodology used and scale of intervention.

Workforce development contributes to lifelong learning, development of proper skills and expertise which can be beneficial to the country's economic development and social welfare, especially considering the globalization phenomenon and Albania's potential in the region. This article is prepared based on secondary research, primarily in the form of literature review. Different literature like articles, reports, surveys, policies, and strategic documents have been consulted in the process of preparing this article.

\section{Workforce Dynamics in Albania}

The transition from a state-run to an open market economy, following the collapse of the communist system in 1991, has faced Albania with a number of social and economic problems due to the changes in the economic structure, failure of state supported industry, rising unemployment and unstable political environment. Such changes were accompanied with high internal and external migration, school drop-out from youth and children, women staying at home, changes in the workforce structure, loss or outdated job skills and uncertainty for the future.

Internal and external migration: Internal migration rates were very high with patterns of movement from rural to urban areas. In 2001 the rural population was 53\%, while in 2011 it had fallen to $46 \%$ of the total population (INSTAT, 2012). Albania has faced high rates of emigration estimated to be overall 1.1 million, since 1990. The population decreased to 2.82 million in 2011 (INSTAT, 2012) and the average age increased from 30.6 years in 2001 to 35.3 years in 2011. Main causes for increased emigration were related to poverty, lack of employment, low wages, poor labor conditions, as well as unpromising perspectives especially related to the economic development. Albanian emigrants have been mainly young males with high levels of education. The destinations that have been chosen by them are mainly Greece (50\%) and Italy (25\%) due to geographical proximity and cultural bonds, as well as USA, UK and other western European countries (25\%) (Siar-et al. 2008). Emigration has affected also a significant group of talented and successful Albanian students remaining abroad after finishing the university or post-graduate studies there.

Employment: The workforce participation rate for the population between 15 to 64 years old for 2013 was 59.9\%. During this year employment rates decreased by $11.2 \%$ compared to the previous year and total employment was dominated by the agricultural sector with about $44.6 \%$ and the services sector with $37.9 \%$. The structure of employment by status showed that employees accounted for $40.2 \%$ of the total employment in 2013, while the self-employed accounted for $25.6 \%$. The contributing family workers accounted for about one-third of the total employment, where females were 1.8 times more likely than males to work as contributing family worker. The informal employment accounted for $43 \%$ of the total employment in non-agricultural sectors.

Unemployment: According to INSTAT (2014) the level of unemployment in Albania in 2013 was $15.6 \%$ showing an increase of 2.2\% compared to the previous year. The unemployment rate for the youth of 15 to 24 years old was $30.2 \%$, showing an increase of $2.3 \%$ compared to the previous year, while the biggest share of unemployment (72.8\%) was accounted by individuals who have been unemployed for more than a year. In 2013, although there has been a decrease in the unemployment rate of people with university education by $1.8 \%$ compared to the previous year, and an increase of the proportion of unemployed individuals with only primary and secondary education, the unemployment rate remains higher for those individuals with university education (about 14.7\%) compared to those with primary (10.2\%) and secondary education (14.2\%).

Employment is considered a great contributor to the economic growth. Policy development, reforms and investment for improvement of workforce knowledge and skills, creating access to job market, as well as the improvement of entrepreneurial environment are key interventions to increasing employment, people welfare and economic growth. Since Albania faces high rates of unemployment amongst youth, the political agenda have recently shown increased attention for vocational education and training as well as reforms for improving the quality of higher education. However, there are a number of questions which need to be considered regarding these reforms:

- How far the curricula and quality provided by the vocational training and higher education, match the needs of the labor market and especially regarding technology improvement and innovation?

- How far is the private sector part of the dialog with educational institutions for deciding on the training curricula and how the quality of the curricula can be improved in order to provide capacities that labor market requires?

- How can the individuals choose proper education considering their career development options? 
Often individuals decide to invest in their education without being certain about what the labor market really needs. As there is limited research on labor market, both individuals searching for educational services as well as entities providing training and education services lack proper information that would help them make the right choice.

Based on other countries experience, the perspective of workforce development can help to overcome such difficulties. Albania has the potential to learn from best practices in this field and to create successful models which will, in return, increase the impact on education and employment, development of policies in an integrated method by bringing together different actors, such as: employers, training institutes, vocational schools, universities and governmental structures, in order to achieve a bigger impact.

\section{Workforce Development Concept}

Workforce development is frequently misunderstood as many people think of it as only job training. The literature shows that there are different definitions for workforce development, however they all aim at: human capital development based on labor market needs and access to employment. Harrison and Weiss (1998) defined workforce development as the "constellation of activities from orientation to the work world, recruitment, placement and mentoring to follow-up counseling and crisis intervention".

Workforce development does not relate only to education and training. Training is only one component of workforce development; however, workforce development approach contributes to a lifelong learning process. Government of South Australia (2003) defines workforce development as 'those activities which increase the capacity of individuals to participate effectively in the workforce throughout their whole working life, and which increase the capacity of firms to adopt high performance work practices that support their employees to develop the full range and their potential skills and values'.

Workforce development has evolved to describe a relatively wide range of national and international policies and programs related to learning for work (Jacobs \& Hawley 2007). The approach does not focus solely on the education and training needs of the individual, but adopts a system based approach to consider the wider issues that need to be understood and addressed to enable the workforce to be developed appropriately (Staron 2008).

According to Jacobs and Hawley (2007) the emergence of workforce development as a new concept comes from the contemporary intersection of five interrelated streams: globalization, technology, the new economy, political change, and demographic shifts. Globalization increases competition between countries due to open markets and is supported through technology, especially information technology which shortens the geographical distances between countries.

The new technologies being introduced create more complexity in the work process, requiring employees to frequently adapt to diverse production requirements.

Workforce development is linked to: entry and/or reentry to labor market, adapting to changes in the labor market and lifelong learning.

According to Haralson (2010) workforce development approach can be viewed from different perspectives:

- From the individual perspective the workforce development is considered as a combination of services, community support, job training and education that positions an individual for success in the workforce. Individuals cannot make a contribution to the society without access to training and education.

- From the society perspective: workforce development is considered as initiatives that train and educate individuals to meet the needs of current and future needs of the labour market, in order to maintain a sustainable competitive economic environment.

- From the organizational perspective: workforce development is defined as training programs that provide existing and potential workers with the skills to complete tasks that support organizations to be competitive in a global marketplace.

In order to achieve greater impact, workforce development requires a higher degree of cooperation between training or education providers, industry, government and individual companies. Buchanan and Hall (2003) argue that it is critical to focus on the industry needs to demand, deploy and develop higher skills.

\section{Different Models for Workforce Development}

Workforce development approach has been widely used in different countries, such as United States, United Kingdom, Singapore, Australia, Germany, etc.

The concept of workforce development in the United States includes a wide range of activities, policies and programs, many of which are indistinguishable from vocational education and training (Jacobs, 2002). The idea of the 
concept is to ensure to the individuals a sustainable livelihood through development of training and skills policy, alongside ensuring that employer's skill demands can be met.

The concept of workforce development in the United Kingdom consists of activities which increase the capacity of individuals to participate effectively in the workforce, thereby improving their productivity and employability. Workforce development is seen as broader in scope than training, but narrower than education as an element of lifelong learning focusing on labor demand. The scope of workforce development in the United Kingdom aims at stimulating development of new skills in order to increase productivity, social inclusion and preparing the economy for the future.

Different models of workforce development have been developed in different countries based on industry, regional and national level. This article explores four models of workforce development.

\section{1 'Sector Panels'}

This model aims at giving employers a guiding role. It has been developed by the King County in Washington State in the United States. The county population in 2010 was 1.93 million people which accounts for about $28 \%$ of Washington state population according to the United States Census Bureau. In order to contribute to workforce development, the county developed a model which relies on the engagement of employers whose input is very important for effective preparation of workers for job openings that will exist in the near future.

The Workforce Development Council of this county developed an effective instrument to build close collaboration with employers - the so called 'Sector Panel' which convenes a group of employers in one particular industry to focus on workforce needs of that industry. The panel is comprised by employers and leaders in the industry who occupy at least $50 \%$ of the seats, as well as training and education agencies, labor unions, economic development agencies and community based organizations.

A sector panel continues for anywhere between 6 to 18 months and begins with a detailed labor market analysis. The panels contribute to labor market survey for the industry, training curricula for preparing workers for future jobs, and a career pathway for entry-level workers. The county has established several sector panels in several industries, such as: healthcare, green construction, interactive media, life sciences, etc. By means of this instrument, the Workforce Development Council of King County has been able to raise financial support from the U.S. Department of Labor for training and education in specific fields.

\section{2 'Strategic Pillars'}

This model was developed by the New Zealand Ministry of Health. It addresses systems and organizational strategies to produce five strategic pillars for workforce development, on which this model is being based. The application of the model is done through projects and programs under each pillar.

- Infrastructure Development - The focus of the model is placed on creating a national and regional infrastructure which supports stakeholders to progress workforce development in an efficient and effective manner. Such infrastructure aims to:

- avoid the risk of delivering inefficient, fragmented and replicated services due to lack of coordination amongst different stakeholders. Such aim is achieved through development of cross-sector functional networks with good lines of communication and coordination.

- develop improved funding mechanisms to support new models of care and training;

- develop programs to monitor the progress and success of workforce development activities and the implementation of workforce policy and regulation.

- Organizational development - The aim is to assist the sector to develop organizational culture and systems necessary to sustain their workforce. Positive organizational cultures and strong leadership contribute to attracting and retaining the employees as well as to achieving high levels of productivity, efficiency and customer satisfaction. The model is based on the philosophy that - during economic difficulties, when the organizations cannot afford to pay higher salaries they can promote healthy workplace practices, positive and flexible workplace environments, and other health, career and personal benefits to employees to attract and retain them.

- Training and development - This pillar is built around coordinating disparate elements of the sector into a framework that is relevant for all parties and with a qualifications framework that meets service provider requirements and takes into account existing competencies.

The need for alignment between educational program providers, professional models of practice and changing 
service delivery needs has been identified as a central issue in this model, and therefore changes to education and training provide the key to successfully implement new models of practice and the new roles that will be needed to increase workforce productivity. In this way, as demand changes over time, the workforce has core sets of highly transferable competencies.

- Retention and recruitment - One of the pillars of the model is to develop a national and regional response to issues of retention and recruitment, providing medium to long-term solutions and therefore reducing reactive and crisis-driven approach. Good recruitment policies ensure that people with the right capacities and the right mix of people are employed within an organization. However recruitment policies can be effective only when there is a pool of appropriately qualified workers to recruit from. Therefore, recruitment policies rest on the foundation of a well-functioning training and education system, and are closely linked to organizational development activities.

Retention is key to the effective use of workforce skills. The reasons for staff turnover vary, but they usually include such things as incentives, rewards and environment, family commitments, retirement, performance, and alternative careers and opportunities. High turnover leads to increased recruitment costs, loss of institutional knowledge, workplace stress, and reductions in the quality of care provided, and in return affect productivity. In order to promote recruitment and retention the model uses different strategies such as:

- $\quad$ branding and career promotion in schools;

- career pathways and professional development;

- $\quad$ providing support to new staff through the transition from training to practice.

- Research and evaluation - This aims to ensure information is available to the sector to inform workforce development and to seek better understanding of the effectiveness of workforce development expenditure. This pillar defines research and evaluation as they relate to the capacity and capability of the workforce, the work produced and the environment or context in which work is carried out.

\subsection{Singapore Workforce Development Agency}

The Singapore Workforce Development Agency is an example of a national agency established to enhance the competitiveness and employability of workers and jobseekers by helping them adapt to a changing economy. To achieve this, the agency works with various industry leaders, labor unions, employers, economic agencies, professional associations and training organizations to develop and implement programs to support Singapore's economic development. Such agency supports the growth of Singapore industries by building a pipeline of competent workers through the constant upgrading of workers' skills and raising industrial performance standards (WDA, 2008).

The Singapore Workforce Development Agency was established in September 2003, during the early 2000s economic crisis to help the workforce cope through training and skills upgrading. Its mission is to "lead, drive and champion workforce development, enhancing the employability and competitiveness of Singapore's workforce".

Some of the programs managed by this agency are:

- Skills Development Fund: This program provides funds to encourage employers in upgrading the skills of the workforce. Funds are accumulated through a skills development levy. The Skills development Fund is managed by the Workforce Development Agency. It offers assistance as an incentive to companies to develop training programs for employees. Incentives are offered on the basis of a cost-sharing principle, while the training must be relevant to the economic development of Singapore and the amount of incentives that a company can obtain is not tied to the levy contribution.

- Skills Development Levy: It is a statutory requirement for employers to make monthly contributions for employees. All the levy funds that are accumulated are channeled to the Skills Development Fund which is used to support workforce upgrading skills programs and to provide training grants to employers when sending their employees to attend training under the national Continuing Training System. The Skills development Levy is managed by the Workforce Development Agency.

- SDF EasyNet: This is a website application system which allows all skill development funds transactions to be made via the internet. This system links up all users of the system, such as companies, training providers and skills development funds for more efficient services.

- Lifelong Learning Endowment Fund: Its objective is to enhance the employment and employability through initiatives that promote and facilitate the acquisition of skills. Such fund can be used to support employerbased, individual-based or community-based training for increased employment and employability. Programs are developed in partnership with industry/trade or employer associations, community organizations, etc. 
Priority is given to programs targeting those who face greater challenges related to structural changes in the economy and labor market.

\section{4 'Rritje Albania'}

'Rritje Albania' literally means 'Grow Albania'. It is a USAID project which was implemented during 2009-2014. Although there have been several projects and programs in the past 20 years in Albania focusing their interventions on improvement of educational system, vocational training, employment, economic growth, etc. little was done in terms of an overarching workforce development approach, as previous initiatives have managed to cover only some elements of the workforce development. 'Rritje Albania' managed to create an integrated methodology which contributes to the economic growth also through a workforce development component. This is a novelty for development program interventions in Albania, given the methodology used and the scale of intervention.

The main objective of the project was to 'Increase sales and create new and better jobs by strengthening the competitiveness of non-agricultural enterprises', therefore contributing to the country economic growth. Workforce development was one of the components of this project which would contribute to the achievement of the overall goal.

The project focused its activities on four key export-oriented industries: tourism, garment, footwear, and information and communications technology. The main components of the project were:

a) Strengthening trade and investment capacity;

b) Increasing enterprise productivity; and

c) Improving workforce development.

The scope of this article is to explore the workforce development concept, therefore only a description of the intervention under this component is included.

The project assisted directly 141 companies which by the end of the project recorded an overall $51 \%$ increase in total sales over their annual baseline taken before receiving project assistance, and $5 \%$ increase in jobs. The intervention of the project was done in different levels and through establishing certain structures. In addition to individual company direct assistance in terms of operations and training, identifying labor demand, increasing jobs and sales, and on the job training, the project played a catalytic and influential role in shaping policy debates and creating new and effective working relations among key industry stakeholders. A working group was established per industry, in order to maximize the project impact and to help continue sustained growth in the target sectors after the project end. These four groups were established:

- Garment and Footwear Working Group;

- Intellectual Property Rights;

- Tourism Group, the Western Balkans GeoTourism Stewardship Council;

- PROTIK ICT Resource Center.

These working groups served as key public-private mechanisms for policy consultation. The project also identified willing and high-potential stakeholders, beneficiaries, intermediaries, collaborators, and partnered with more than 75 public and private institutions. In doing so, the project aimed to leverage resources and capitalize on synergies to achieve more positive outcomes and greater impact.

In order to sustain the results realized in industry and firm-level competitiveness, 'Rritje Albania' undertook a number of 'key legacy initiatives'. The ones that contribute to workforce development are related to improved quality of workforce through training and education:

- Hotel Certified Programs: 'Rritje Albania' worked to improve professional standards in Albania's hospitality sector through improved training and education programs for tourism and universities. The project established partnerships between the American Hotel, Lodging Educational Institute and one Albanian NGO to offer certified hospitality training programs for working tourism professionals; and a partnership with a private university in Albania to establish diploma programs in tourism.

- Responding to industry needs through University programs, Vocational education and industry partnerships: The project paired foreign experts with the Textile and Fashion Department at the Polytechnic University of Tirana (the one of the kind in Albania) to increase the ability of the university faculty to conduct consultancies; promote graduates in this program; improve testing and laboratory facilities; strengthen internship and career counseling programs; introduce technical curriculum enhancements, including the addition of footwear and leather topics in diploma programs; and develop lifelong learning courses.

With the assistance of the project, the university cooperated with three vocational schools to develop a new garment design course using computer-aided design and computer-aided manufacturing (CAD/CAM) 
technology. With the assistance of the project, Lectra Modaris, a world leader in CAD/CAM, provided 16 software licenses free-of-charge, while garment firms in Albania donated used sewing machines to vocational schools that previously had no production equipment. The project helped to establish partnerships between private and educational sector, therefore contributing to reduce the gap between the workforce skill supply and demand which had previously constrained industry competitiveness.

- Career offices: Although the law of higher education requires the establishment of career offices at universities, in most cases they are formal and inexistent. 'Rritje Albania' led a successful initiative to create new career development offices at five large universities. These centers provide students with career counseling, internships, and help with job placement, thereby create sustainable links between schools and employers.

\section{Conclusions}

The economic success of a country is strongly linked to the skills, talent and capacities of its human capital. The levels of education, the ability to access the job market, the growing need for continuous learning throughout lifetime, have become an imperative for economic growth. Globalization and fast changes in technology, especially in the information technology, require that the workforce is under a continuous learning and training process. However, not always the training and education programs fully comply with labor market needs and therefore the impact of training and education in economic growth is affected.

Workforce development approach would maximize the contribution of different stakeholders to reduce the gap between the level of skills provided by the workforce and the ones demanded by the labor market. However, workforce development is not only based on skill supply, but also on improving the mechanisms by which employers needs for skills can be effectively communicated to training and education providers. Workforce development includes multiple interventions in different aspects of legislation, policy, recruitment and retention and different support mechanisms for implementation. A successful workforce development is characterized by effective communication mechanisms and partnerships between public and private education and training providers, employers and industry representatives, labor unions, employment agencies and governmental agencies.

International experience has shown that workforce development creates greater impact at economic growth, especially at times of economic constraints. Given the current dynamics of the Albanian economy, workforce development integrated approach would create better impact for policy and reforms in terms of education and employment growth. An integrated approach would maximize the impact of investment, since the coordination amongst stakeholders would avoid replication and fragmented services. Workforce development provides proper mechanisms to match workforce skills with current and future labor market demand, and therefore contributes to economic growth.

\section{References}

Ashton, D. ad Green, F. (1999). Education and training for development in East Asia: The political economy of skill formation in newly industrialized economies. London, Routledge.

Buchanan, J \& Hall, R (2003) Beyond VET: The Changing Skill Needs of the Victorian Services Industries, Volume 1 Summary Report, Melbourne: Department of Education and Training.

Government of South Australia (2003). Skills South Australia, Final Report of the Ministerial Inquiry, Adelaide.

Haralson E., Lyn (2010). What is Workforce Development? www.stlouisfed.org

Harrison, B., Weiss, M., and Gant, J. (1995) Building Bridges: Community Development Corporations and the World of Employment Training, The Ford Foundation, New York.

Harrison, B.; Weiss, M. 1998. Workforce development networks: community based organizations and regional alliances. Thousand Oak, CA: Sage Publications.

INSTAT (2012), Population and Housing Census Albania 2011. www.instat.gov.al

INSTAT (2014) Labour market report 2013. www.instat.gov.al

Jacobs, RL (2002). Understanding Workforce Development: Definition, Conceptual Boundaries, and Future Perspectives. International Conference on Technical and Vocational Education and Training, UNEVOC, Canada.

Jacobs, RL \& Hawley, J (2007). Emergence of Workforce Development: Definition, Conceptual Boundaries and Implications. Centre on Education \& Training for Employment, Ohio State University, Columbus, USA.

Siar, Sh. (ed.), Chindea, A., Majkowska-Tomkin, M., Mattila. H. and Pastor, I., (2008): Migration in Albania: A country profile 2008, International Organization for Migration, Geneva.

Staron, M (2008) Workforce Development - a whole-of-system model for workforce development. Tafe NSW, Ezine.

Sutton, A. (2001) Corporate - Community Workforce Development Collaborations. New York: Community Development Research 
Center, New School University.

USAID (2014). Rritje Albania. Competitiveness Enterprise Development Project. Final Report.

WDA (2008). About WDA, Singapore Workforce Development Agency.

Center for an Urban Future www.nycfuture.org

New Zealand Ministry of Health www.health.govt.nz

United States Census Bureau. www.quickfacts.census.gov/qfd/states/53/53033.html 